\title{
Gender difference in betel quid consumption levels and tobacco use among adults in Myanmar
}

Yin Min Aye, Seo Ah Hong, Bang-on Thepthien, Sariyamon Tiraphat

ASEAN Institute for Health Development, Mahidol University, Thailand

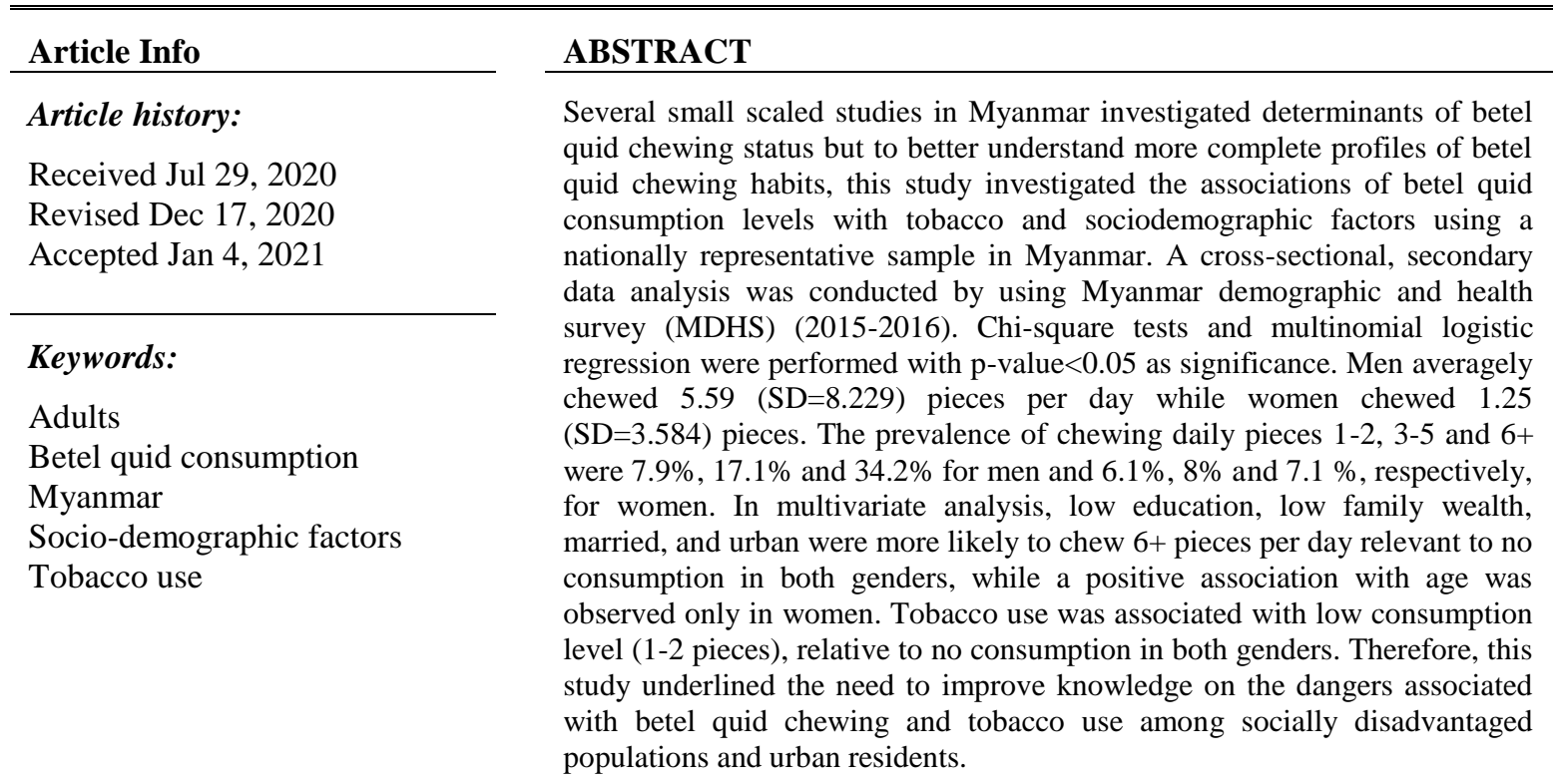

This is an open access article under the CC BY-SA license.

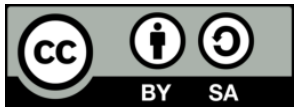

\section{Corresponding Author:}

Yin Min Aye

ASEAN Institute for Health Development

Mahidol University

Salaya, Phuthamonthon, Nakhon Pathom 73170, Thailand

E-mail: smurfyinmin123@gmail.com

\section{INTRODUCTION}

Betel quid is the combination of various substances such as areca nut, betel leaf, catechu, spices, sweetener, slaked lime, and with or without tobacco [1]. Since $10 \%$ of the world population chew betel quid, predominantly in South and Southeast Asia, and Asia pacific regions, the betel quid chewing makes it one of the most widely used psychoactive substance like caffeine and nicotine [2]. As noted and released by the International Agency for Research on Cancer, betel quid consumption regardless of tobacco causes cancer in humans such as oral cancers [3]. In Myanmar, the prevalence of betel quid chewing among men and women aged 15-49 years were $59 \%$ and $18 \%$, respectively in $2015-16$ [4].

During the period from 2009 to 2014, smokeless tobacco use such as betel quid chewing increased among both men and women and the increasing trend was more prominent among women when comparing to men in all age groups [5]. Therefore, this study was conducted to identify determinants related to betel quid consumption levels by gender. Moreover, during this period, as compared to smoking, smokeless tobacco use such as betel quid chewing was higher among men and women [5]. Thus, this study examines whether there is any 
association of betel quid consumption levels with tobacco use. Myanmar is currently experiencing a double burden of both communicable and non-communicable diseases. NCDs account for seven of the ten main causes of death, and are responsible for $68 \%$ of all deaths [6]. And oral cancer accounts for $3.5 \%$ of whole body cancer [7]. The incidence and mortality rates of oral cancer were 6.2 and 3.8 per 100,000 populations per annum, respectively, that were the highest as compared to Southeast Asian countries [8]. Ministry of health and sports (MoHS) has established a number of relevant policies to support sustainable development goals (SDG) three which is "ensure healthy lives and promote well-being for all at all ages". In addition, several strategic plans of the most recent national health plan (NHP) cover assistance to target population such as NCDs since rates of NCDs are particular concern to MoHS [9]. Moreover, tobacco control programme, one of the priority programmes of NHP, was officially launched in January 2000. It implemented promotion of community awareness through all forms of media in collaboration with the Ministry of Information, media personnel and through national non-government organizations (NGOs). Nevertheless, there are misconceptions of smokeless tobacco use including betel quid chewing as less dangerous products than smoking tobacco. Thus, this is a big challenge for the tobacco control measures, along with the very low prices of smokeless tobacco products [10].

To reduce the prevalence of NCDs and to strengthen NCDs prevention and control, it is necessary not only to implement a well-developed national policy to reduce betel quid chewing but also to perform the effective activities such as ongoing health education about the diseases caused by betel quid consumption which take into account the predictors related to betel quid consumption levels. Several small scaled studies [11-15] in Myanmar investigated determinants of betel quid chewing status but to better understand more complete profiles of betel quid chewing habits, this study investigated the associations of betel quid consumption levels with tobacco and sociodemographic factors using a nationally representative sample in Myanmar. The objective of this study is to examine betel quid consumption levels and its associations with socio-demographic factors and tobacco use by gender among adults aged 18- 49 years old in Myanmar. The finding from this study is expected to support the NCDs related goals of SDG three such as 1) to reduce one third premature mortality from NCDs, and 2) to strengthen the implementation of WHO framework convention on tobacco control, and tobacco control programme of NHP by implementing a more comprehensive national policy including the limitation of number of daily chewing pieces along with betel quid related health promotion and education programs, which especially take into consideration these socio-demographic factors related to betel quid consumption levels.

\section{RESEARCH METHODS}

\subsection{Study design and subjects}

We conducted a cross-sectional, secondary data analysis using Myanmar demographic health survey (MDHS) (2015-2016) [4]. MDHS was the first survey and implemented by ministry of health and sports (MoHS) from December 2015 to July 2016. It consisted of 4,000 primary sampling units (PSUs), and thus, is a large, nationally representative sample. It was based on the 2014 census frame and created under the aegis of the Department of Population within the Ministry of Labor, Immigration and Population. In order to allow estimates of core indicators at the national level, and in urban and rural areas, the sample for this survey was selected by a stratified two-stage sampling. At the first stage, a total of 441 clusters (122 urban and 319 rural) consisting of enumeration area (EAs) or wards/village tracts was selected. The second stage involved a fixed number of 30 households which were selected from each of the selected clusters (total of 13,230 households), using equal probability systematic sampling.

In MDHS, a total of 12,885 women and 4,737 men aged 15-49 years from 12,500 households participated. $96 \%$ of women and $91 \%$ of men, respectively responded the questionnaires of MDHS [4]. After those aged under 18 years old were excluded, a total of 11,773 women and 4,251 men from 12,500 households were included in the analyses for this current study. After the permission to use the MDHS data in this analysis was obtained from Opinion Research Corporation Macro Inc, the datasets of the MDHS can be downloaded freely and were accessed from the DHS website. Details of these MICS have been described elsewhere [16].

The original study was carried out after all procedures involving research study participants were approved by the Ethics Review Committee on Medical Research including Human Subjects in the Department of Medical Research, MoHS, Myanmar and written informed consent was obtained from all subjects. The data source kept the confidentiality and anonymity of personal information, such as the names, addresses, locations of the study participants. This present study of secondary data analyses was exempted from a full review and was approved by the Institutional Review Board, Institute for Population and Social Research, Mahidol University, Thailand (Approval No. 2020/03-108).

\subsection{Variables measures}

The outcome variable is number of pieces of betel quid chewing per day obtained from the question "In the last 24 hours, how many pieces did you chew" and is categorized into four consumption levels $(0,1-2,3-5,6+)$. Independent variables are sociodemographic factors such as age, education attainment, occupation, 
wealth index, marital status, native language, geographical factors such as types of residence and any tobacco use. Wealth index is used to assess household socioeconomic status, as described in the corresponding country's latest and available DHS reports [17]. The wealth index was calculated using the data on a household's ownership of the selected assets based on the number and kinds of consumer goods they owned, such as a television and car, dwelling characteristics such as the flooring material, types of drinking water sources, toilet facilities, and other characteristics related to wealth. Households were given scores using principal component analysis of the assets owned by households in urban and rural area [17]. The score was divided into five equal quintiles with the first, representing the poorest $20 \%$, and the fifth, representing the richest $20 \%$. For the variable "tobacco use", three questions, such as "Do you currently smoke cigarettes?" and "do you currently smoke or use any (other) type of tobacco?" with response (No or Yes) and "What (other) type of tobacco do you currently smoke or use?" with response options (pipe/cigar/cheroot, chewing tobacco, snuff, and other) were asked. Those currently using any type of tobacco (cigarette, cigar, pipe, cheroot, snuff by mouth, chewing tobacco, other types of tobacco) were categorized as tobacco users (no or yes) for the analysis.

The independent variables included in the analyses were coded as follows: current age (18-29 years, 30-39 years, 40-49 years), education attainment (no education/incomplete primary, complete primary, incomplete secondary, complete secondary/higher), occupation (professional/technical/managerial/clerical, agricultural, household and domestic/not working, services/sales, skilled manual, and unskilled manual), native language (Myanmar or non-Myanmar), wealth index quintiles (poorest, poorer, middle, richer, richest), marital status (married or living without spouse: union/widowed/divorced/separated), any tobacco use (no or yes), and types of residence (rural or urban).

\subsection{Data analysis}

Statistical package for social sciences (SPSS) version-21 was used to carry out statistical analyses. Univariate analysis was performed to describe sampled population according to socio-demographic variables, types of residence, and tobacco use. Bivariate analysis was performed to identify the associations of betel quid consumption levels with each independent variable by using Chi-square test. Multinomial logistic regression analysis was done to estimate adjusted odds ratio (AOR) to identify the strong predictors related to betel quid consumption levels. P-value $<0.05$ was considered as significance. In addition, we calculated Spearman correlation coefficient ( $r$ ) between number of pieces of betel quid chewing and number of cigarettes within last 24 hours among men and women.

\section{RESULTS AND DISSCUSSION}

\subsection{Results}

On average, men chewed $5.59(\mathrm{SD}=8.229)$ betel quid pieces per day while women chewed 1.25 $(\mathrm{SD}=3.584)$ pieces. The prevalence of chewing daily pieces one up two, three up five and six or above were $7.9 \%, 17.1 \%$ and $34.2 \%$ for men and $6.1 \%, 8 \%$ and $7.1 \%$, respectively, for women. Mean of age were 33.02 years $(\mathrm{SD}=9.107)$ for men and $33.11(\mathrm{SD}=9.03)$ for women, respectively. As shown in Tables 1 and 2, more than two thirds of adults were under 40 years old and with occupation of agriculture/services/manual jobs and married, also speak Myanmar language, and live in rural areas. Those with no formal education or incomplete primary school were $31.1 \%$ in men and $37.2 \%$ in women. $45.3 \%$ of men reported tobacco use, while only $5.7 \%$ of women reported. Table 1 and 2 also describe bivariate association of number of pieces of betel quid chewing with socio-demographic factors and tobacco use among men and women aged 18-49 years. The prevalence of consumption levels was significantly associated with age, education attainment, occupation, wealth index, marital status, native language, types of residence and tobacco use among men and women $(\mathrm{p}<0.01)$.

Table 1. Bivariate association between sociodemographic factors and tobacco use and number of pieces of betel quid among men aged $18-49$ years

\begin{tabular}{|c|c|c|c|c|c|c|c|}
\hline \multirow{3}{*}{ Independent variables } & \multirow{2}{*}{\multicolumn{2}{|c|}{ Total }} & \multicolumn{4}{|c|}{ Men } & \multirow[b]{3}{*}{ p-value } \\
\hline & & & 0 & $1-2$ & $3-5$ & $6+$ & \\
\hline & Number & $\%$ & $\%$ & $\%$ & $\%$ & $\%$ & \\
\hline & 4251 & $100 \%$ & 40.8 & 7.9 & 17.1 & 34.2 & \\
\hline Age & & & & & & & 0.002 \\
\hline $18-29$ & 1659 & 39.0 & 40.3 & 46.1 & 39.8 & 35.5 & \\
\hline $30-39$ & 1345 & 31.6 & 29.8 & 31.3 & 32.1 & 33.7 & \\
\hline $40-49$ & 1247 & 29.3 & 29.9 & 22.6 & 28.0 & 30.8 & \\
\hline Education & & & & & & & $<0.0001$ \\
\hline No education/Incomplete primary & 1324 & 31.1 & 29.6 & 38.4 & 33.5 & 30.1 & \\
\hline Complete primary & 739 & 17.4 & 15.3 & 16.4 & 18.8 & 19.4 & \\
\hline Incomplete secondary & 1670 & 39.3 & 40.0 & 39.3 & 37.4 & 39.4 & \\
\hline Complete secondary/Higher & 518 & 12.2 & 15.1 & 6.0 & 10.3 & 11.1 & \\
\hline Occupation & & & & & & & $<0.0001$ \\
\hline
\end{tabular}




\begin{tabular}{|c|c|c|c|c|c|c|c|}
\hline Professional/technical/managerial/clerical & 390 & 9.2 & 11.7 & 5.4 & 8.9 & 7.3 & \\
\hline Agricultural (self-employed/employed) & 1167 & 27.5 & 27.7 & 35.2 & 30.8 & 23.9 & \\
\hline Household and domestic/Not working & 137 & 3.2 & 5.0 & 1.8 & 3.0 & 1.6 & \\
\hline Services/Sales & 354 & 8.3 & 7.7 & 5.4 & 5.7 & 11.1 & \\
\hline Skilled manual & 909 & 21.4 & 20.6 & 16.7 & 17.0 & 25.7 & \\
\hline Unskilled manual & 1285 & 30.3 & 27.4 & 35.5 & 34.6 & 30.4 & \\
\hline Wealth index & & & & & & & $<0.0001$ \\
\hline Poorest & 803 & 18.9 & 14.8 & 26.5 & 23.1 & 19.9 & \\
\hline Poorer & 841 & 19.8 & 19.4 & 20.5 & 21.4 & 19.2 & \\
\hline Middle & 897 & 21.1 & 21.2 & 23.2 & 22.3 & 20.0 & \\
\hline Richer & 893 & 21.0 & 22.6 & 16.4 & 19.2 & 21.1 & \\
\hline Richest & 817 & 19.2 & 22.0 & 13.4 & 14.0 & 19.9 & \\
\hline Marital status & & & & & & & $<0.0001$ \\
\hline Adults without spouse & 1339 & 31.5 & 36.3 & 34.8 & 29.4 & 26.0 & \\
\hline Married & 2912 & 68.5 & 63.7 & 65.2 & 70.6 & 74.0 & \\
\hline Native language & & & & & & & $<0.0001$ \\
\hline Myanmar & 3706 & 87.2 & 86.3 & 81.8 & 84.8 & 90.7 & \\
\hline Other & 544 & 12.8 & 13.7 & 18.2 & 15.2 & 9.3 & \\
\hline Types of residence & & & & & & & $<0.0001$ \\
\hline Urban & 1195 & 28.1 & 30.0 & 17.3 & 20.7 & 32.1 & \\
\hline Rural & 3056 & 71.9 & 70.0 & 82.7 & 79.3 & 67.9 & \\
\hline Any tobacco use & & & & & & & $<0.0001$ \\
\hline No & 2326 & 54.7 & 52.8 & 35.4 & 51.5 & 63.0 & \\
\hline Yes & 1925 & 45.3 & 47.2 & 64.6 & 48.5 & 37.0 & \\
\hline
\end{tabular}

Table 2. Bivariate association between sociodemographic factors and tobacco use and number of pieces of betel quid among women aged $18-49$ years

\begin{tabular}{|c|c|c|c|c|c|c|c|}
\hline \multirow{3}{*}{ Independent variables } & \multirow{2}{*}{\multicolumn{2}{|c|}{ Total }} & \multicolumn{4}{|c|}{ Women } & \multirow[b]{3}{*}{ p-value } \\
\hline & & & \multirow{2}{*}{$\begin{array}{l}0 \\
\%\end{array}$} & \multirow{2}{*}{$\begin{array}{c}1-2 \\
\%\end{array}$} & \multirow{2}{*}{$\begin{array}{c}3-5 \\
\%\end{array}$} & \multirow{2}{*}{$\begin{array}{l}6+ \\
\%\end{array}$} & \\
\hline & Number & $\%$ & & & & & \\
\hline & 11773 & 100 & 78.8 & 6.1 & 8.0 & 7.1 & \\
\hline Age & & & & & & & $<0.001$ \\
\hline $18-29$ & 4496 & 38.2 & 42.4 & 32.2 & 20.7 & 16.7 & \\
\hline $30-39$ & 3889 & 33.0 & 31.7 & 35.0 & 37.4 & 41.0 & \\
\hline $40-49$ & 3388 & 28.8 & 25.9 & 32.9 & 41.9 & 42.2 & \\
\hline Education & & & & & & & $<0.0001$ \\
\hline No education/Incomplete primary & 4383 & 37.2 & 31.8 & 53.1 & 61.0 & 57.2 & \\
\hline Complete primary & 2046 & 17.4 & 17.2 & 18.4 & 18.0 & 17.8 & \\
\hline Incomplete secondary & 5384 & 30.4 & 33.1 & 22.4 & 18.2 & 21.9 & \\
\hline Complete secondary/Higher & 1758 & 14.9 & 17.9 & 6.1 & 2.9 & 3.1 & \\
\hline Occupation & & & & & & & $<0.0001$ \\
\hline Professional/technical/managerial/clerical & 1009 & 8.6 & 10.1 & 3.1 & 1.7 & 4.0 & \\
\hline Agricultural (self-employed/employed) & 1765 & 15 & 14.7 & 17.0 & 19.0 & 12.6 & \\
\hline Household and domestic/Not working & 3158 & 26.9 & 26.2 & 27.7 & 33.2 & 27.2 & \\
\hline Services/Sales & 2264 & 19.3 & 19.2 & 21.6 & 14.6 & 23.8 & \\
\hline Skilled manual & 783 & 6.7 & 7.4 & 3.5 & 3.3 & 5.5 & \\
\hline Unskilled manual & 2766 & 23.6 & 22.5 & 27.1 & 28.2 & 26.8 & \\
\hline Wealth index & & & & & & & $<0.0001$ \\
\hline Poorest & 2158 & 18.3 & 13.8 & 32.9 & 38.8 & 32.5 & \\
\hline Poorer & 2228 & 18.9 & 18.0 & 22.8 & 23.5 & 21.2 & \\
\hline Middle & 2394 & 20.3 & 20.9 & 20.2 & 17.4 & 17.7 & \\
\hline Richer & 2505 & 21.3 & 23.0 & 15.7 & 13.7 & 15.8 & \\
\hline Richest & 2488 & 21.1 & 24.3 & 8.4 & 6.6 & 12.9 & \\
\hline Marital status & & & & & & & $<0.0001$ \\
\hline Adults without spouse & 3973 & 33.7 & 36.7 & 27.2 & 20.9 & 21.3 & \\
\hline Married & 7800 & 66.3 & 63.3 & 72.8 & 79.1 & 78.7 & \\
\hline Native language & & & & & & & $<0.0001$ \\
\hline Myanmar & 9868 & 83.8 & 86.9 & 69.5 & 69.7 & 77.9 & \\
\hline Other & 1905 & 16.2 & 13.1 & 30.5 & 30.3 & 22.1 & \\
\hline Types of residence & & & & & & & $<0.0001$ \\
\hline Urban & 3443 & 29.2 & 31.8 & 17.4 & 16.2 & 25.9 & \\
\hline Rural & 8330 & 70.8 & 68.2 & 82.6 & 83.8 & 74.1 & \\
\hline Any tobacco use & & & & & & & $<0.0001$ \\
\hline No & 11106 & 94.3 & 96.3 & 85.1 & 84.7 & 91.3 & \\
\hline Yes & 667 & 5.7 & 3.7 & 14.9 & 15.3 & 8.7 & \\
\hline Adults without spouse $=$ Never in union $/ \mathrm{W}$ & parated & & & & & & \\
\hline ny tobacco use $=$ cigarette, cigar, pipe, $\mathrm{ch}$ & h, chewi & b & 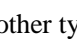 & 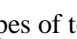 & & & \\
\hline
\end{tabular}


Tables 3 and 4 describe the AORs for one up two, three up five and six or above pieces relative to no consumption for the covariates considered in the multivariate analysis among men and women respectively. In Table 3, as compared to younger men, older men were 0.54 times less likely to chew one up two pieces, and 0.76 times less likely to chew three up five pieces relative to no consumption. Men with no education and with incomplete secondary education, those with agricultural/self-employed/employed occupation and tobacco users were more likely to chew one up two pieces relative to no chewers. Those with poorest wealth quintile and those married were more likely to chew three up five pieces per day relative to no chewers. In light of six or more pieces per day, men completing primary education, with services/sales, skilled manuals and unskilled manuals, the poorest, married, Myanmar language speakers, living in urban area were more likely to chew, relative to no chewers, while men with no job/domestic workers and tobacco users were less likely to chew six or more pieces per day, relative to no chewers.

Table 3. Multivariate association between socio-demographic factors and tobacco use and number of pieces of betel quid chewing among men aged $18-49$ years

\begin{tabular}{|c|c|c|c|c|c|c|c|c|c|}
\hline & \multicolumn{9}{|c|}{ Men } \\
\hline & \multicolumn{3}{|c|}{$1-2$ vs. 0} & \multicolumn{3}{|c|}{$3-5$ vs. 0} & \multicolumn{3}{|c|}{$6+$ vs. 0} \\
\hline & AOR & \multicolumn{2}{|c|}{$95 \% \mathrm{CI}$} & AOR & \multicolumn{2}{|c|}{$95 \%$ CI } & AOR & \multicolumn{2}{|c|}{$95 \% \mathrm{CI}$} \\
\hline Age & & & & & & & & & \\
\hline $18-29$ & 1.00 & & & 1.00 & & & 1.00 & & \\
\hline $30-39$ & 0.79 & $(0.59-$ & $1.07)$ & 0.91 & $(0.73-$ & $1.15)$ & 1.03 & $(0.85-$ & 1.24) \\
\hline $40-49$ & 0.54 & $(0.38-$ & $0.75)$ & 0.76 & $(0.60-$ & $0.97)$ & 0.92 & $(0.76-$ & $1.13)$ \\
\hline \multicolumn{10}{|l|}{ Education } \\
\hline No education/Incomplete primary & 1.82 & $(1.03-$ & $3.24)$ & 1.04 & $(0.72-$ & $1.50)$ & 1.13 & $(0.84-$ & $1.51)$ \\
\hline Complete primary & 1.66 & $(0.91-$ & $3.05)$ & 1.18 & $(0.80-$ & 1.74) & 1.37 & $(1.01-$ & $1.86)$ \\
\hline Incomplete secondary & 1.73 & $(1.02-$ & 2.96) & 1.08 & $(0.78-$ & $1.50)$ & 1.15 & $(0.89-$ & $1.48)$ \\
\hline Complete secondary/Higher & 1.00 & & & 1.00 & & & 1.00 & & \\
\hline \multicolumn{10}{|l|}{ Occupation } \\
\hline Professional, technical, managerial/ Clerical & 1.00 & & & 1.00 & & & 1.00 & & \\
\hline Agricultural (self-employed/employed) & 1.79 & $(1.00-$ & 3.19) & 1.08 & $(0.75-$ & $1.57)$ & 1.23 & $(0.90-$ & 1.69) \\
\hline Household and domestic/Not working & 0.74 & $(0.28-$ & $1.95)$ & 0.85 & $(0.49-$ & $1.48)$ & 0.59 & $(0.35-$ & $1.00)$ \\
\hline Services/Sales & 1.43 & $(0.71-$ & 2.90) & 0.96 & $(0.61-$ & $1.52)$ & 2.15 & $(1.53-$ & $3.02)$ \\
\hline Skilled manual & 1.35 & $(0.75-$ & 2.44) & 0.96 & $(0.66-$ & $1.40)$ & 1.84 & (1.36- & $2.48)$ \\
\hline Unskilled manual & 1.76 & (0.99- & $3.13)$ & 1.23 & $(0.85-$ & $1.77)$ & 1.55 & (1.14- & 2.10) \\
\hline \multicolumn{10}{|l|}{ Wealth index } \\
\hline Poorest & 1.41 & $(0.87-$ & 2.29) & 1.81 & $(1.26-$ & $2.62)$ & 1.84 & $(1.37-$ & 2.46) \\
\hline Poorer & 0.91 & $(0.57-$ & $1.47)$ & 1.33 & $(0.93-$ & $1.88)$ & 1.29 & $(0.98-$ & $1.69)$ \\
\hline Middle & 1.04 & $(0.66-$ & $1.64)$ & 1.33 & $(0.95-$ & $1.86)$ & 1.17 & $(0.90-$ & $1.51)$ \\
\hline Richer & 0.80 & $(0.51-$ & $1.25)$ & 1.15 & $(0.84-$ & $1.58)$ & 1.10 & $(0.87-$ & 1.39) \\
\hline Richest & 1.00 & & & 1.00 & & & 1.00 & & \\
\hline \multicolumn{10}{|l|}{ Marital status } \\
\hline Adults without spouse & 1.00 & & & 1.00 & & & 1.00 & & \\
\hline Married & 1.07 & $(0.80-$ & 1.42) & 1.35 & $(1.09-$ & 1.69) & 1.54 & $(1.28-$ & 1.84) \\
\hline \multicolumn{10}{|l|}{ Native language } \\
\hline Myanmar & 0.96 & $(0.69-$ & 1.34) & 1.04 & $(0.81-$ & $1.35)$ & 1.54 & $(1.22-$ & 1.96) \\
\hline Other & 1.00 & & & 1.00 & & & 1.00 & & \\
\hline \multicolumn{10}{|l|}{ Types of residence } \\
\hline Urban & 0.71 & $(0.49-$ & 1.02) & 0.83 & $(0.64-$ & $1.08)$ & 1.30 & (1.07- & $1.58)$ \\
\hline Rural & 1.00 & & & & & & & & \\
\hline \multicolumn{10}{|l|}{ Any tobacco use } \\
\hline Yes vs. No & 1.98 & $(1.54-$ & 2.53) & 1.01 & $(0.85-$ & $1.21)$ & 0.63 & $(0.54-$ & $0.73)$ \\
\hline \multicolumn{10}{|l|}{$\mathrm{AOR}=$ Adjusted odds ratio } \\
\hline \multicolumn{10}{|c|}{ Adults without spouse $=$ Never in union/Widowed/Divorced/Separated } \\
\hline \multicolumn{10}{|c|}{ Any tobacco use $=$ cigarette, cigar, pipe, cheroot, snuff by mouth, chewing tobacco, other types of tobacco } \\
\hline No consumption $(0)$ is a reference group & & & & & & & & & \\
\hline
\end{tabular}

In women, as shown in Table 4, age of women was positively associated with number of pieces of betel quid. There is an inverse association between number of pieces of betel quid and education levels and wealth index quintiles. As compared to professionals, women with no job, services/sales, were more likely to chew one up two pieces and three up five pieces relative to no consumption. Additionally, farmers (AOR 1.96, 95\% CI=1.12-3.43) and unskilled manuals (AOR 1.96, 95\% CI=1.13-3.40) chewed three up five pieces per day over no consumption than professionals, while farmers were less likely to consume six or more pieces. Marital status showed the increasing trend of betel quid consumption among women. Relative to no consumption, married women were 1.30 times more likely to chew three up five pieces, and 1.36 times more likely to chew six above as compared to women without spouse. Likewise, women in urban area (AOR 1.54, 95\% $\mathrm{CI}=1.25-1.89$ ) chewed six above pieces per day more than those in rural area relative to no consumption. Additionally, relative to no consumption, women in native tone in Myanmar were less likely to chew as compared to non-Myanmar. In light of tobacco use, women tobacco users were 2.40 times more 
likely to chew one up two pieces, and 1.98 times more likely to chew three up five pieces as compared to non-users relative to no consumption. Figure 1 describes the correlation between number of pieces of betel quid chewing and number of cigarettes among men and women. For men, number of pieces of betel quid chewing per day was negatively correlated with number of cigarettes with the Spearman correlation coefficient $(r=-0.169, \mathrm{p}<0.001)$ but there is no correlation among women $(r=0.09, p=0.1390)$.

Table 4. Multivariate association between socio-demographic factors and tobacco and betel quid chewing among women aged $18-49$ years

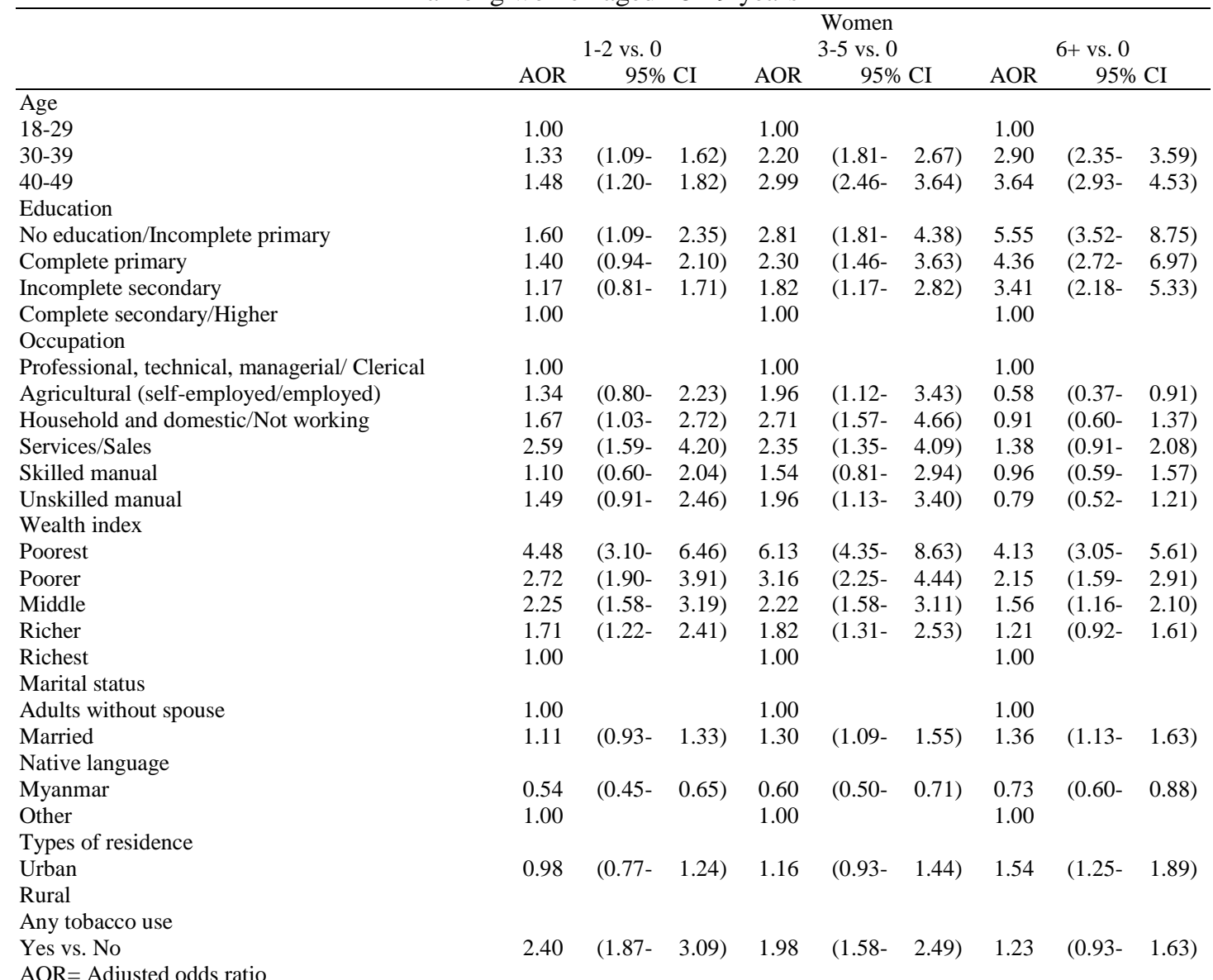

Adults without spouse $=$ Never in union/Widowed/Divorced/Separated

Any tobacco use $=$ cigarette, cigar, pipe, cheroot, snuff by mouth, chewing tobacco, other types of tobacco

No consumption (0) is a reference group
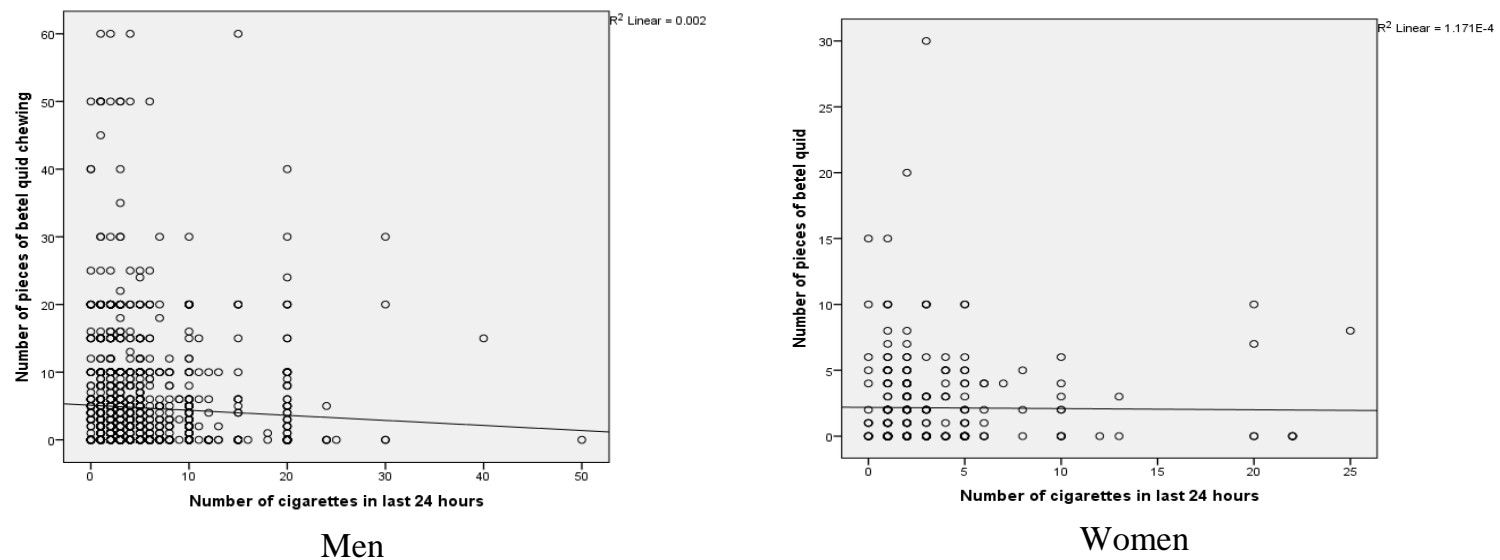

Figure 1. Correlation between number of pieces of betel quid chewing and number of cigarettes in last 24 hours among men $(r=-0.169, \mathrm{p}<0.001)$ and women $(r=-0.09, \mathrm{p}=0.1390)$ 


\subsection{Discussion}

This study identified the prevalence of betel quid consumption levels per day at national level. This study also found the positive association of high consumption level with low socio-economic status such as low education, occupation, and low family wealth, geographical factors such as urban area, marital status such as those living with spouse, and the positive association of low consumption level with tobacco use among men and women based on a nationally representative sample of MDHS (2015-2016). On average, men chewed 5.59 ( $\mathrm{SD}=8.229)$ betel quid pieces per day while women chewed $1.25(\mathrm{SD}=3.584)$ pieces. In comparison with Myanmar STEPwise approach to surveillance (STEPS) report in 2014, men chewed 11.3 pieces and women chewed 7.3 pieces per day, respectively among adults aged 25-64 years old [18]. This similar result was found in one study in Solomon Islands which reported that men chewed significantly higher pieces of quid $(13.2 \pm 32.8)$ per day than women $(4.8 \pm 4.8 ; \mathrm{p}<0.01)$ [19]. By contrast, one study in Bangladesh reported that women chewed more pieces than men [20]. One study in Lao also reported that Laotin women were observed to frequently chew 7-10 pieces of betel quid per day [21].

Our study reported that the prevalence of chewing daily pieces one up two, three up five and six above were $7.9 \%, 17.1 \%$ and $34.2 \%$ for men and $6.1 \%, 8 \%$ and $7.1 \%$, respectively, for women. It can be seen that majority of betel quid chewers consumed 6 or more pieces in our study. This result is in line with other previous study from Myanmar, where $2 \%$ of the respondents chewed only one up two quid per day and $74 \%$ of the respondents chew six or more pieces regardless of gender [15]. That is probably because, in Myanmar, there is a common misconception that smokeless tobacco use including betel quid chewing is less harmful than cigarettes smoking [10]. In multivariate analysis, low education, low family wealth, marital status such as those living with spouse, and urban residents were the strong determinants of high betel quid consumption level (six above pieces) in both genders. Although there is difficulty in direct comparison with other studies due to little studies analyzed factors related to betel quid consumption levels, many studies showed that there was a positive association of betel quid use with age [20, 22], low education attainment in Myanmar [14, 23], Bangladesh [22] and Taiwan [24], manual workers in Taiwan [24], low family wealth in Nepal [25] and India [26], and those living with spouse in Taiwan [27]. While age of men was inversely associated with consumption levels among men, age of women is positively associated with number of pieces of betel quid. As compared to the youngest, older women were more likely to chew six above pieces relevant to no consumption. That can be explained by men from Myanmar were more likely to engage in multiple risk behaviors, such as smoking tobacco and drinking alcohol, and chewing betel quid whereas women are more likely to perform only one such behavior [28] and by the prevalence of daily number of cigarettes which increased with age among men whereas the percentage of daily number of cigarettes decreased with age among women in Myanmar [18]. One study in Bangladesh, however, reported that betel quid pieces increased with age peaking in the 50-59 year age group regardless of gender [22]. Likewise, another study from rural Bangladesh identified that number of pieces of betel quid per day increased among older people (>40 years) in comparison with those $<40$ years [20]. Concerning education attainment, number of pieces of betel quid increased with the decrease in education level among men and women in our study. Men and women with lower education level are more likely to chew high consumption level (daily pieces six above). The result of our study was similar to one study in Solomon Islands, which reported that less educated adults chewed higher consumption level than adults with tertiary education (13 vs. 7 quids per day) [29] and one study among Bangladeshi women which showed that more educated women chewed lower number of pieces of betel quid significantly [30]. By contrast, multiple regression models of one study in Bangladesh showed that there was no effect of education on the frequency of betel quid use after controlling for other variables [22].

In term of occupation, this study identified that men with services/sales, skilled manuals and unskilled manuals were more likely to chew six above relative to no consumption as compared to professional men while women with agricultural jobs, services/sales, unskilled manuals were more likely to chew three up five pieces. That may be due to their belief of smokeless tobacco products consumption including betel quid chewing as a way to maintain "attention" and "focus," and also they mention that it can help them work harder, and work for longer periods [31]. Likewise, one study in Bangladesh revealed that businessmen took it significantly more frequently than the non-paid, farmers and professionals [22]. However, one study among Bangladeshi women reported that there was no association between daily betel quid chewing pieces and occupation [30]. In term of wealth index, men and women with the poorest wealth quintile were more likely to chew six above pieces per day over no consumption as compared to the richest. That can be explained by the price (four pieces= MMK 100/- or 0.025 USD per piece) of betel quid which is cheaper and affordable to low-income workers because their average minimum daily income is around 2000 MMK (1.42 US dollars) [15]. In addition, higher tax on cigarettes $(75 \%)$ and lower tax on betel quid with tobacco $(20 \%)$ can lead the poor to use betel quid more [10]. According to the WHO global tobacco report, in Myanmar, cigarette affordability became decreased in 2014-2016 [32]. However, one study from Bangladesh 
reported that there was no association between numbers of pieces of betel quid per day with land ownership [20]. Regarding marital status, men and women living with spouse were more likely to chew six above relative to no consumption as compared to those without spouse. This result is in contrast with multiple regression models of one study in Bangladesh did not show any effect of marital status on the frequency of betel quid use after controlling for other variables [22]. Regarding native language, as compared to nonMyanmar, men in native tone of Myanmar were more likely to chew six above relative to no consumption whereas women in native tone of Myanmar were less likely to chew six above pieces over no consumption. However, one study among Bangladeshi women reported that there was no significant association of number of pieces of betel quid chewing per day among women speaking different languages [30]. In term of types of residence, our study reported that, relative to no consumption, men and women in urban chewed 6 or more pieces per day more than those in rural areas. This is because there are strategically placed kiosks selling betel quid at every public location including schools, theaters, offices, markets, hospitals, clinics, university campuses, bus stops, and restaurants in Myanmar. In addition, prepackaged betel quid are sold at major traffic junctions [31]. Similar result was found in one study done in Bangladesh which reported that urban respondents chewed betel quid more frequently [22]. In contrast, one study among Bangladeshi women reported that types of residence were not significantly associated with number of pieces of betel quid chewing per day [30].

Additionally, tobacco users were more likely to chew one up two pieces over no consumption as compared to nonusers among both men and women. Those using both tobacco products and betel quid may be more likely to addict to nicotine and less likely to quit or have intention to quit [33]. This finding is in contrast with one study from Bangladesh, which reported that number of pieces of betel quid consumption was highest among non-tobacco users [20]. In this study, men tobacco users were less likely to chew six pieces or more relevant to no consumption as compared to non-users. That can be probably explained by smoking as a predominant habit among men in Myanmar and over three-fourth of men use tobacco in one or another form [5]. Moreover, we reported that number of pieces of betel quid chewing was negatively correlated with number of cigarettes within last 24 hours among men but not women. Because there were little studies for correlation between number of pieces of betel quid chewing and number of cigarette, it was difficult to compare the result with other studies. However, one study from Taiwan National Health Interview Survey found that betel quid chewing and cigarette smoking were positively correlated each other among adults $(\mathrm{r}=0.81, \mathrm{p}<0.001)$ [34] and the study done among males in Taiwan showed that the daily quantity of betel quid chewing was positively correlated with the daily quantity of smoking $(r=0.314, p<0.01)$ [35].

There are some limitations in our study. First, due to the nature of the cross-sectional study design, causal inferences are allowed. Second, as it was a secondary data analysis, we could not examine the relationship between number of pieces of betel quid chewing and duration of betel quid consumption, and other characteristics related to betel quid consumption levels. Third, as there were only two questions asking the information of betel quid chewing in the MDHS questionnaire, this study did not provide sufficient information on betel quid chewing behaviors among Myanmar people. This study recommends the MDHS to ask additional questions regarding betel quid consumption such as "How long does chewer consume betel quid?" "When did chewer start chewing?" and "Why does chewer consume betel quid?" Lastly, the outcome variable was categorized into four consumption levels, and was not the continuous variable; this study could not identify the linear effect of socio-demographic factors and tobacco use on the outcome variable. However, this study was the first study to provide the better profile of betel quid chewing by examining betel quid consumption levels and its associations with socio-demographic factors and tobacco use based on a nationwide representative sample of Myanmar population. This study provides some suggestions based on the findings. First, due to the strong associations of socio-demographic factors with betel quid consumption levels among men and women, the MoHS should effectively implement the community awareness programs about betel quid chewing and its effects on health, particularly taking into consideration low socio-economic status and types of residence.

Second, since 2017, smoking-free zone campaign has been conducted in four regions (Yangon, Mandalay, Sagaing and Magway) and in 2018, three more regions (Ayeyarwady, Bago and Mon) joined to the campaign [36]. Effort has been paid to tackle smoking in public places, aligning with tobacco control of 2030 Agenda for SDG [36]. A multicenter case-control study showed that the dual practice of betel quid consumption regardless of tobacco and smoking tobacco has additive interaction effect on risk of oral, oropharyngeal, and/or esophageal cancer [37]. As this study found that tobacco users were more likely to chew 1-2 pieces over no consumption as compared to non-tobacco users among both men and women, this study recommends that Myanmar government should provide education programs about the health consequences related to both tobacco use and betel quid consumption to the dual users. 


\section{CONCLUSION}

This study found that a high level of betel quid consumption is positively associated with low socioeconomic status and urban in both genders. Tobacco use was positively associated with low consumption levels in both genders. This study underlines the need to improve knowledge on the dangers associated with betel quid chewing and tobacco use among socially disadvantaged populations and urban residents.

\section{ACKNOWLEDGEMENTS}

The authors thank to Demographic Health and Survey Program for providing dataset to carry out this study and to write manuscripts. This paper is partial fulfillment for Yin Min Aye for the requirements for the degree of Master of Primary Health Management, ASEAN Institute for Health Development, Mahidol University.

\section{REFERENCES}

[1] Gupta PC, Warnakulasuriya S., "Global epidemiology of areca nut usage," Addiction biology, vol. 7, no. 1, pp. 7783, 2002. doi: 10.1080/13556210020091437. PubMed PMID: 11900626.

[2] Gupta PC, Ray CS., "Epidemiology of betel nut use," Annals Academy Medicine Singapore, vol. 33, no. 4 Suppl, pp. 31-6, 2004.

[3] Health risks of betel quid and tobacco. Tobacco control law and consortium, 2017.

[4] Ministry of Health and Sports (MoHS) and ICF. Myanmar Demographic and Health Survey 2015-16. Nay Pyi Taw, Myanmar, and Rockville, Maryland USA: Ministry of Health and Sports and ICF, 2017.

[5] Sinha DN, Bhartiya D., Kumar A., Singh H., Mehrotra R., "Men in Myanmar Submerged in Tobacco: Women Following," Nicotine Tobacco Research., vol. 19, no. 11, pp. 1397-8, 2017, doi: 10.1093/ntr/ntw314.

[6] Myanmar Health \& Development Consortium. Myanmar health status, 2018. [Online]. Available: https://myanmarhdc.org/myanmar-health-status/.

[7] Oo HN, Myint YY, Maung CN, Oo PS, Cheng J., Maruyama S., et al. "Oral cancer in Myanmar: a preliminary survey based on hospital-based cancer registries," Journal of Oral Pathology and Medicine, vol. 40, no. 1, pp. 20-6. 2011. doi: 10.1111/j.1600-0714.2010.00938.x.

[8] Cheong SC, Vatanasapt P., Yi-Hsin Y., Zain RB, Kerr AR, Johnson NW., "Oral cancer in South East Asia," Translational Research In Oral Oncology, p. 1-9, 2017. doi: 10.1177/2057178x17702921.

[9] SDG 3 Good health and well-being, 2020. [Online]. Available: https://opendevelopmentmyanmar.net/topics/sdg-3good-health-and-well-being/.

[10] Brief profile on tobacco control in Myanmar 2009. [Online]. Available: http://origin.searo.who.int/tobacco/documents/en/.

[11] Htin Kyaw, Isao I, Koichi K., "Effect of belief and knowledge on betel quid chewing behavior in Myanmar: Variation across socio-economic status," Kōkūbyō Gakkai zassh, vol. 86, no. 3, pp. 53-70, 2019.

[12] Min Htike, Maung Maung Naing, "Comparison on knowledge, attitude, and practice of betel nut chewing habit between blind and normal people in Yangon," 6th Asian Academic Society International Conferenc (AASIC), 2018.

[13] Marquez P., Krasovsky K., Andreeva T., "Myanmar: Overview of tobacco use, tobacco control, legislation, and taxation," World Bank Group and Global Tobacco Control Program, 2019.

[14] Ar Kar, Win Myint Oo, Chomar Kaung Myint, Khaymar Mya., "Knowledge and practice of betel quid chewing in urban area of Than-Daung Town, Kayin State," Burma Medical Journal, vol. 57, no. 4, pp. 40-6, 2015.

[15] A study on the betel nut and tobacco chewing habits in Yangon 2019. [Online]. Available: https://webcache.googleusercontent.com/search?q=cache:nGZuv9Orrx4J:https://meral.edu.mm/record/1676/file_pr eview/Kyaw\%2520Zin\%25200o\%2520MPA.pdf $+\& \mathrm{~cd}=7 \& \mathrm{hl}=\mathrm{en} \& \mathrm{ct}=\mathrm{clnk} \& \mathrm{gl}=\mathrm{mm}$.

[16] U.S. Agency for International Development (USAID). The Demographic and Health Surveys Program: U.S. Agency for International Development (USAID), 2020. [Online]. Available: https://dhsprogram.com/Data/termsof-use.cfm.

[17] Croft TN, Aileen M. J. Marshall, Courtney K. Allen, et al., "Guide to DHS Statistics," Rockville, Maryland, USA: ICF, 2018.

[18] Report on national survey of diabetes milletus and risk factors of non-communicable diseases in Myanmar 2014. [Online]. Available from: https://www.who.int/ncds/surveillance/steps/myanmar/en/.

[19] Tovosia S., Chen PH, Ko AM, Tu HP, Tsai PC, Ko YC., "Prevalence and associated factors of betel quid use in the Solomon Islands:A hyperendemic area for oral and pharyngeal cancer," Journal of The American Society of Tropical Medicine and Hygiene, vol. 77, no. 3, pp. 586-90, 2007.

[20] Heck JE, Marcotte EL, Argos M., et al., "Betel quid chewing in rural Bangladesh: prevalence, predictors and relationship to blood pressure," International Journal Epidemiology, vol. 41, no. 2, pp. 462-71, 2012. doi: 10.1093/ije/dyr191.

[21] Asma S., "Smokeless tobacco: betel quid chewing among adult women in Lao People's Democratic Republic," Tobacco control, vol. 6, no. 2, pp. 157-8, 1997. doi: 10.1136/tc.6.2.157.

[22] Floraa MS, Mascie-Taylorb CG, Rahmanc M., "Betel quid chewing and its risk factors in Bangladeshi adults," WHO South East Asia Journal Public Health, vol. 1, no. 2, pp. 169-81, 2012. 
[23] Su Kyaw Myint, Narksawat K., Sillabutra J., "Prevalence and factors influencing betel nut chewing among adults in west insein township, Yangon, Myanmar," Southeast Asian J Trop Med Public Health, vol. 47, no. 5, pp. 1089-97, 2016.

[24] Ko Y., Chiang T., Chang S., Hsieh S., "Prevalence of betel quid chewing habit in Taiwan and related sociodemographic factors," Journal Oral Pathology Medicine, vol. 21, no. 6, pp. 261-4, 1992. doi: 10.1111/j.16000714.1992.tb01007.x.

[25] Sreeramareddy CT, Ramakrishnareddy N., Kumar HH, Sathian B., Arokiasamy JT., "Prevalence, distribution and correlates of tobacco smoking and chewing in Nepal: a secondary data analysis of Nepal Demographic and Health Survey-2006," Subst Abuse Treat Prev Policy., vol. 6, no. 33, pp. 1-9, 2011. doi: 10.1186/1747-597X-6-33.

[26] Rani M., Bonu S., Jha P., Nguyen S., Jamjoum L., "Tobacco use in India: prevalence and predictors of smoking and chewing in a national cross sectional household survey," Tobacco Control, vol. 12, no. 4, p. e4, 2003, doi: 10.1136/tc.12.4.e4.

[27] Lin C., Wang J., Chen P., et al., "Predictors of betel quid chewing behavior and cessation patterns in Taiwan aborigines," BMC Public Health, vol. 6, no. 1, p. 271, 2006. doi: 10.1186/1471-2458-6-271.

[28] Kyaw Htin, Howteerakul N, Suwannapong N., Tipayamongkholgul M., "Smoking, alcohol consumption and betelquid chewing among young adult Myanmar laborers in Thailand," Southeast Asian Journal of Tropical Medicine and Public Health, vol. 45, no. 4, pp. 926-39, 2014.

[29] Pratt S., "The challenge of betel nut consumption to economic development: a case of Honiara, Solomon Islands," Asia-Pacific Development Journal, vol. 21, no. 2, pp. 103-20, 2014.

[30] Nunez-de la Mora A., Jesmin F., Bentley GR., "Betel nut use among first and second generation Bangladeshi women in London, UK," J Immigr Minor Health., vol. 9, no. 4, pp. 299-306, 2007. doi: 10.1007/s10903-007-9041-2.

[31] Sein T., Sein TO, Swe T., et al.,"Challenge of smokeless tobacco use in Myanmar," Indian Journal of Cancer, vol. 51, no. 5, pp. 3-7, 2014.

[32] World Health Organization. WHO report on global tobacco epidemic, 2017.

[33] Kram Y., Klesges R., Ebbert J., et al., "Dual tobacco user subtypes in the U.S. Air Force: dependence, attitudes, and other correlates of use," Nicotine Tob Res., vol. 16, no. 9, pp. 1216-23, 2014, doi: 10.1093/ntr/ntu056.

[34] Huang YT, Ho PS, Jou YY, Wu CY, Wang YW, Yang YH., "Determining High Prevalence of Betel-Quid Chewing and Cigarette Smoking by Occupation Using the Taiwan National Health Interview Survey," Substance Use \& Misuse, vol. 55, no. 9, pp. 1472-82, 2020. doi: 10.1080/10826084.2020.1732421.

[35] Chen M-L, Yang K-L, Chen H-S, et al., "Prevalences of betel nut chewing and cigarette smoking among male prisoners before their imprisonment in Taiwan," Journal of Dental Sciences, vol. 7, no. 2, pp. 165-70, 2012, doi: 10.1016/j.jds.2012.03.014.

[36] Southeast Asia Tobacco Control Alliance: ASEAN Tobacco Control Resource Center. Myanmar: Three more regions to join smoking-free zone campaign: Southeast Asia Tobacco Control Alliance: ASEAN Tobacco Control Resource Center; 14 My 2018. [Online]. Available: https://seatca.org/myanmar-three-more-regions-to-joinsmoking-free-zone campaign/\#: :text=According\%20to\%20a\%202014\%20survey,or\%20other\%20forms\%20of\%20tobacco.

[37] Akhtar S, Sheikh AA, Qureshi HU., "Chewing areca nut, betel quid, oral snuff, cigarette smoking and the risk of oesophageal squamous-cell carcinoma in South Asians: a multicentre case-control study," Eur J Cancer., vol. 48, no. 5, pp. 655-61, 2012, doi: 10.1016/j.ejca.2011.06.008. 